\title{
A GESTÃO DE PESSOAS E AS ESTRATÉGIAS DE ATRAÇÃO, DESENVOLVIMENTO E RETENÇÃO DE PROFISSIONAIS: O CASO PETROBRAS
}

MANAGEMENT OF PEOPLE AND STRATEGIES OF ATTRACTION, DEVELOPMENT AND RETENTION: THE PETROBRAS CASE

\section{LA GESTIÓN DE PERSONAS Y ESTRATEGIAS DE ATRACCIÓN Y RETENCIÓN DE DESARROLLO PROFESIONAL: EL CASO PETROBRAS}

\section{Nildes Pitombo Leite}

Doutora em Administração pela Faculdade de Economia, Contabilidade e Administração da Universidade de São Paulo - FEA/USP

Professora do Programa de Pós Graduação em Administração da Universidade Nove de Julho PPGA/UNINOVE

E-mail: nildesrpl@uninove.br (Brasil)

\section{Fabio Pitombo Leite}

Doutor em Mathematical Behavioral Sciences pela University of California, Irvine, Estados Unidos Professor da The Ohio State University, Lima , Estados Unidos

E-mail: leite.11@osu.edu (Estados Unidos)

\section{Lindolfo Galvão de Albuquerque}

Doutor em Administração Universidade de São Paulo - USP

Professor da Universidade de São Paulo - USP

E-mail: lgdalbuq@usp.br (Brasil) 


\title{
A GESTÃO DE PESSOAS E AS ESTRATÉGIAS DE ATRAÇÃO, DESENVOLVIMENTO E RETENÇÃO DE PROFISSIONAIS: O CASO PETROBRAS*
}

\author{
*Pesquisa Financiada pela FAPESP
}

\section{RESUMO}

Este estudo de caso, ancorado na abordagem qualitativa e com nível de análise organizacional, investigou a gestão de pessoas dentro de unidades com estruturas organizacionais remotas (i.e., longe dos centros urbanos) e não remotas da PETROBRAS - Petróleo Brasileiro S/A. A pesquisa foi realizada em três plataformas marítimas, três bases e na unidade operacional da selva Amazônica, envolvendo 31 respondentes, entre diretores, gerentes, profissionais de $\mathrm{RH}$, supervisores e coordenadores. Esses respondentes são representativos para o nível de análise escolhido, bem como para a estratégia de pesquisa. Seu foco esteve voltado para dois problemas principais, considerados igualmente relevantes: Como gerenciar pessoas em unidades distantes das principais sedes da organização? Como gerenciar essas pessoas de modo a assegurar os objetivos estratégicos de atrair, desenvolver e reter o capital humano valorizado nessas unidades? A coleta dos dados primários foi feita por meio de entrevistas em profundidade e observações; a dos dados secundários, por meio de análise de documentos. Trabalhou-se com as estratégias das análises de conteúdo, documental e reflexiva. Seus resultados indicaram as especificidades de políticas e práticas de gestão de pessoas, oriundas das estratégias de atração, desenvolvimento e retenção de profissionais nessas unidades, especificidades essas que representam contribuição para a área de gestão de pessoas.

Palavras-chave: Gestão Estratégica de Pessoas; Estratégias de Atração; Desenvolvimento e Retenção; Estruturas Organizacionais Remotas.

\section{MANAGEMENT OF PEOPLE AND STRATEGIES OF ATTRACTION, DEVELOPMENT AND RETENTION: THE PETROBRAS CASE}

\section{ABSTRACT}

This case study examined the management of people in remote units (i.e., far from urban centers) and in urban units of PETROBRAS - Petróleo Brasileiro S/A. Specifically, this research was performed in three offshore platforms, three bases, and in the Amazon jungle's unit, interviewing 31 employees that included directors, managers, HR professionals, supervisors, and coordinators. The following two questions were addressed: How to manage people working in units far away from the main headquarters of the organization? How to manage them in order to assure the organizational strategic objectives of attracting, developing and retaining valuable human capital in these units? The primary data collection was done by means of interviews and observations, and the data were analyzed via content analysis. The results indicated that the specific policies and practices for managing people, based on the strategies for attracting, developing, and retaining the professionals working in the studied units, are advantageous, illustrating effective policies and practices to the field of strategic people management.

Keywords: Strategic People Management; Strategies of Attraction; Development and Retention; Remote Organizational Structures. 


\section{LA GESTIÓN DE PERSONAS Y ESTRATEGIAS DE ATRACCIÓN Y RETENCIÓN DE DESARROLLO PROFESIONAL: EL CASO PETROBRAS}

\section{RESUMEN}

Este estudio de caso, anclada en el enfoque cualitativo y el nivel de análisis de la organización , investigó la gestión de las personas dentro de las unidades con las estructuras organizativas a distancia (es decir, lejos de los centros urbanos ) y no a distancia PETROBRAS - Petróleo Brasileiro S / A. La encuesta se realizó en tres plataformas en alta mar, tres bases y de funcionamiento de la selva amazónica, con la participación 31 encuestados, incluidos los directores, gerentes, profesionales de recursos humanos, supervisores y coordinadores. Estos encuestados son representativos para el nivel deseado de análisis, así como la estrategia de investigación. Su enfoque se enfrenta a dos problemas principales se consideran igualmente relevantes : Dirección de Personas en las unidades distantes de la sede principal de la organización? ¿Cómo estas personas logran garantizar los objetivos estratégicos de atraer, desarrollar y retener el capital humano valioso en estas unidades ? La recolección de datos primarios se realizó a través de entrevistas y observaciones, los datos secundarios a través del análisis de los documentos . Trabajamos con las estrategias del análisis de contenido, documental y reflexivo. Sus resultados indican las políticas y prácticas específicas para la gestión de personas, que se derivan de estrategias para atraer, desarrollar y retener a los profesionales de estas unidades, que representan éstos contribución específica al campo de la gestión de personas.

Palabras-clave: Gestión de Personas Estratégico; Estrategias de Atracción; Desarrollo y Retención; Estructuras Organizacionales Remoto. 


\section{INTRODUÇÃO}

A composição das equipes organizacionais é responsável por limitar ou desafiar a atuação dos gestores das organizações. Por sua vez, a cultura organizacional é a aglutinadora dessa composição. As intervenções dos responsáveis pela gestão de pessoas podem conduzir à obtenção de possíveis respostas à questão de como deveria desenvolver-se o campo do comportamento organizacional e da gestão de pessoas, de modo a privilegiar a indivisibilidade dos indivíduos para o alcance dos resultados organizacionais.

Esses resultados organizacionais podem ser alcançados por intermédio de um sistema de gestão de pessoas bem definido ou apropriado. Para tanto, esses responsáveis pela gestão de pessoas necessitam entender as características essenciais dos indivíduos dentro do contexto organizacional, de modo a obter melhor entendimento na aplicação das ferramentas dessa gestão.

Considerando-se que o contexto organizacional é único, mas a estratégia de gestão de pessoas pode variar de acordo com a forma como as organizações estejam estruturadas, o que diferencia o estudo das organizações com estruturas organizacionais remotas, dos estudos de novas formas de organização do trabalho ou de internacionalização e gestão de recursos humanos internacionalizados dentro de filiais em países estrangeiros, distantes, portanto, dos países de origem das organizações?

Há situações em que a organização, dentro de contextos culturais semelhantes, em termos de cultura de país e cultura organizacional, cria uma infra-estrutura necessária à instalação das pessoas em uma dada região, distante dos grandes centros urbanos, para operar suas unidades lá instaladas. Essas situações diferem dos casos de internacionalização ou de novas formas de organização do trabalho e, as razões dessa diferenciação são as especificidades da estrutura organizacional (departamentalização, comunicações e atribuições) para gerenciar essa infra-estrutura, não obstante as matrizes ou sedes emanem as diretrizes para toda a organização. Essas especificidades são as responsáveis pela denominação de estrutura organizacional remota. Essa denominação pode ter derivações, como remota confinada e remota isolada

Essa estrutura foi considerada como critério de escolha das unidades de análise desta pesquisa, componentes de uma mesma organização - a Petrobras - Petróleo Brasileiro S/A. Além das quatro unidades remotas e confinadas foram consideradas três unidades não remotas, que são as bases de apoio às estruturas organizacionais remotas aqui estudadas. Ressalta-se que essa organização não é a única com estrutura organizacional remota a ser estudada. O que a torna interessante para ser escolhida como unidade de análise nesta pesquisa é o fato de ter estruturas remotas e confinadas em mar e selva, o que permite investigar novas especificidades em um e outro contexto. 
O objetivo desta pesquisa foi investigar a gestão de pessoas dentro de unidades com estruturas organizacionais remotas da Petrobras, especificamente, na Unidade de Negócio Rio - UN Rio, onde estão inseridas uma base em Macaé e as três plataformas marítimas offshore para a produção e exploração de óleo (P40, P38 e PIV) e na Unidade de Negócio Amazônia - UN AM, onde estão inseridas a base e a unidade operacional da selva Amazônica (Urucu). Sua importância reside em responder à questão do que pode favorecer a atração, o desenvolvimento e a retenção de profissionais nessas unidades remotas.

O conjunto dos 31 sujeitos respondentes desta pesquisa foi composto por diretores, gerentes, profissionais de RH, supervisores e coordenadores. Esse conjunto foi considerado representativo para o nível de análise escolhido - o organizacional, bem como para a estratégia de pesquisa adotada - o estudo de caso.

\section{A GESTÃo dE PESSOAS E AS ESTRATÉGIAS DE ATRAÇÃO, DESENVOLVIMENTO E RETENÇÃO}

Contextualiza-se nesta pesquisa que, a gestão de pessoas nas organizações permanece com o status de tema recorrente e desafiador para os pesquisadores, pelas seguintes razões: esse construto considera, também, o tratamento das pessoas com relação às questões de comprometimento, adaptabilidade e alta qualidade (Guest, 1987); do ponto de vista de função, a gestão de pessoas continua a ser apontada como uma das funções-chave para o desenvolvimento e a implementação de respostas estratégicas (Schuler e Jackson, 1987; Schuler, 1992; Ulrich, 1997; Yeung e Berman, 1997; Wright e Snell (2001); ainda é crescente a descoberta da necessidade de valorização do capital humano como fonte de valor e de competitividade organizacional (Ulrich, 1997; 1998; 2000; Dessler, 2003; Albuquerque, 1999; Albuquerque e Leite, 2009; Ulrich e Ulrich, 2011; Ulrich, Allen, Brockbank, Younger e Nyman 2011; Demo, Neiva, Nunes e Rozzett, 2012; Demo, 2012); parte da pesquisa em gestão de pessoas toma por base o comportamento dos empregados como elementochave das estratégias de gestão de pessoas (Steyaert e Janssens, 1999; Davel e Vergara, 2001; Casado, 2002; 2007; Martín-Alcázar, Romero-Fernádez e Sánchez-Gardey, 2005; 2008; Leite, Leite e Albuquerque, 2012; Leite e Albuquerque, 2012); no contexto das unidades com estruturas organizacionais remotas há uma agenda de pesquisas a ser explorada (Leite e Albuquerque, 2009a; 2009b; 2011). 
A Gestão de Pessoas e as Estratégias de Atração, Desenvolvimento e Retenção de Profissionais: O Caso Petrobras

Nesse status de tema recorrente e desafiador a observação sobre a evolução do conceito de administração estratégica de recursos humanos já era respaldada por Albuquerque (1999) e Davel e Vergara (2001), a partir de uma visão sistêmica, em que esses autores sugeriram que diversos subsistemas - a estrutura organizacional, as relações de trabalho e as políticas de RH - comporiam a gestão de pessoas. Esses subsistemas, compostos de estratégias, políticas, práticas e filosofias globais de gestão de pessoas, poderiam ser combinados de forma a produzir estratégias de gestão de pessoas apropriadas e que se encaixassem na estratégia organizacional.

Nessa perspectiva, organizações bem-sucedidas reconheceriam que, incrementos na qualidade e flexibilidade requerem níveis de comprometimento, responsabilidade e conhecimento por parte da força de trabalho, que não podem ser obtidos por coerção ou por 'melhorias cosméticas' nas políticas de recursos humanos (Dertouzos, Lester, e Solow, 1990). Esses autores reconheceram a relevância do comprometimento da força de trabalho das organizações. Sugeriram que os gestores pudessem demonstrar comprometimento com valores, por meio dos seus próprios comportamentos e pelo modo como reforçassem o comprometimento de outros. Recomendaram que o processo de mobilização do comprometimento devesse ser iniciado no topo da organização, dentro do círculo dos principais executivos, com abertura para que outros executivos participassem do processo de reformulação da cultura organizacional e da internalização da visão dessa cultura. Nesse contexto, deveriam estar incluídos o profissional de RH e o escopo do seu papel como parceiro estratégico.

Para que possa ser compreendida a essência desse escopo, é preciso retomar o modelo de múltiplos papéis proposto por Ulrich (1998) e adentrar pelos quatro papeis definidos por ele como os de RH, especialmente, o de administração de infra-estrutura da organização, cujo papel tradicional do especialista administrativo consiste em conceber e desenvolver processos adequados para contratar, treinar, avaliar, premiar, promover e gerir o fluxo de funcionários na organização. Em consequência e complementarmente, entender o que Becker, Huselid e Ulrich (2001) argumentaram acerca dos seguintes fatos: os profissionais de $\mathrm{RH}$ estariam aptos para exercer o papel de parceiro estratégico e agregar valor à organização, quando compreendessem o funcionamento do negócio a ponto de poderem adaptar as políticas e práticas de RH às mudanças nas condições organizacionais; o caráter estratégico da gestão de pessoas pressupõe o alinhamento de recursos humanos com a estratégia organizacional, englobando missão, visão, estratégias, objetivos e planos. Esses fatos corroboram a visão de Anthony, Perrewé e Kacmar (1996) sobre a integração da estratégia de gestão de pessoas com a estratégia organizacional e demais estratégias funcionais. 
Essa integração contribui para a agregação de valor à organização, obtida por meio de participação dos profissionais, em todos os níveis da organização e, em especial, os de RH, na formulação da estratégia organizacional. Autores como (Albuquerque, 1987, 2002; Anthony, Perrewé e Kacmar, 1996; Ulrich, 1998; Becker, Huselid e Ulrich, 2001) entenderam ser esse o novo papel do RH. No que tange à formulação dessa estratégia, Albuquerque (2002) considerou relevante aprofundar os aspectos relativos às dimensões humanas. Nesses aspectos estão contempladas as pessoas, a cultura organizacional e a estrutura.

Com a contemplação desses aspectos, as exigências de gestão e sua consequente obtenção de comprometimento, estão implícitas em valorização das pessoas, confiança na administração e respeito pelas pessoas, como aspectos a serem incluídos nos estudos de comprometimento, conforme elucidado por Dessler (1996). O autor abordou, ainda, a importância de metas confluentes entre organização e trabalhador, de modo a obter o comprometimento do funcionário e reforçou que a criação desse comprometimento pode ajudar a competir, com mais eficácia, em períodos prósperos e a reagir a condições adversas.

Em última instancia, Dessler (1996) referiu-se a aspectos imbricados como envolvimento, participação, compromisso, engajamento, decisão e escolha e referiu-se à comunicação como um dos principais fatores de comprometimento, enfatizando o ouvir e a confiança como bases de efetivação da comunicação de mão dupla. Esses aspectos também fazem parte do repertório de Salancik (1977), o qual apontou três elementos fundamentais para gerar comprometimento: a volição, a visibilidade e a irreversibilidade das ações. Ele enfatizou por fim, que esses elementos contêm sentimento e responsabilidade com o curso da ação escolhido.

Ambos os autores trouxeram a base para as estratégias de atração, desenvolvimento e retenção de pessoas fortalecerem-se nas organizações. Já há algum tempo tem sido exigido que essas organizações se tornem capazes de captar, reter e desenvolver profissionais aptos a adaptar-se às exigências do meio no qual atuam, como foi enfatizado por Ulrich (1998). Foi acrescentado por Friedman (2007) que atrair, desenvolver e reter profissionais qualificados, onde quer que eles estejam localizados no mundo, estão entre os desafios mais comuns enfrentados pelos profissionais de gestão de pessoas. 
A Gestão de Pessoas e as Estratégias de Atração, Desenvolvimento e Retenção de Profissionais: O Caso Petrobras

\section{CONTEXTUALIZAÇÃO DA ORGANIZAÇÃO PESQUISADA}

Fundada no dia 3 de outubro de 1953, a criação da Petrobras foi formalizada, com o objetivo de exercer o monopólio estatal do petróleo no Brasil, em nome da União. As operações de exploração e produção de petróleo, bem como as demais atividades ligadas ao setor de petróleo, gás natural e derivados, à exceção da distribuição atacadista e da revenda no varejo pelos postos de abastecimento, foram monopólio conduzido pela Petrobras de 1954 a 1997. Durante esse período a organização tornouse líder em comercialização de derivados no País. Depois de exercer, por mais de 40 anos, o monopólio estatal do petróleo no Brasil, a Petrobras passou a competir com outras organizações estrangeiras em 1997. A partir daí foram criadas a Agência Nacional do Petróleo - ANP, responsável pela regulação, fiscalização e contratação das atividades do setor e o Conselho Nacional de Política Energética, órgão encarregado de formular a política pública de energia. No dia 21 de abril de 2006, o presidente Luiz Inácio Lula da Silva deu início à produção da plataforma P-50, no Campo de Albacora Leste, na Bacia de Campos, o que permitiu ao Brasil atingir autosuficiência em petróleo.

Além das atividades da holding, o Sistema Petrobras inclui subsidiárias - organizações independentes com diretorias próprias, interligadas à sede. Sua visão até 2020 é assim expressa: "Seremos uma das cinco maiores organizações integradas de energia do mundo e a preferida pelos nossos públicos de interesse.” Sua missão: “Atuar, de forma segura e rentável, com responsabilidade social e ambiental, nos mercados nacional e internacional, fornecendo produtos e serviços adequados às necessidades dos clientes e contribuindo para o desenvolvimento do Brasil e dos países onde atua.”

Compõem a política e diretrizes de Recursos Humanos da organização: atrair e desenvolver; treinar e reter pessoas, investindo em seus talentos e aprimorando as competências técnicas e gerenciais, sem perder de vista o atendimento à dinâmica dos negócios e a sustentação da excelência competitiva; assegurar efetivos adequados aos objetivos dos negócios e promover práticas de compensação competitivas em relação ao mercado; estimular uma cultura organizacional única e humanizada, que respeite os valores locais, valorize a consolidação e troca de conhecimentos e priorize o reconhecimento pelos resultados das equipes e das pessoas; estimular e reconhecer o exercício da cidadania pelos trabalhadores e apoiar as iniciativas vinculadas à responsabilidade social do Sistema Petrobras; manter um processo permanente de negociação para a construção de soluções com a representação sindical dos empregados; adequar as práticas de contratação de serviços, compatibilizando-as com as Políticas de RH, Gestão do Conhecimento, SMS e de Segurança da Informação sobre os negócios e atividades do Sistema Petrobras. 
A política de gestão da Unidade de Negócio Rio é descrita da seguinte forma: "A UN-Rio, tendo como missão explorar e produzir óleo e gás nas concessões sob sua responsabilidade, declara-se comprometida com a melhoria contínua do seu Sistema de Gestão, visando a excelência do desempenho, através dos seguintes compromissos com as partes interessadas: assegurar aos acionistas e parceiros a rentabilidade e a agregação de valor ao negócio de E\&P; atender as demandas dos clientes em relação à produção, contribuindo com a cadeia de valor da Petrobras; assegurar à força de trabalho, a excelência na gestão de recursos humanos, bem como atingir padrões internacionais de segurança e saúde no trabalho; desenvolver as atividades com responsabilidade social, em conformidade com a legislação e demais requisitos subscritos pela Petrobras, atingindo padrões internacionais de prevenção à poluição; aprimorar as relações com fornecedores e incentivar a melhoria do seu desempenho.”

A base operacional de Macaé é a responsável pela operacionalização de plataformas ligadas a UN Bacia de Campos e UN Rio. As plataformas pesquisadas foram: P40, P38 e PIV. A plataforma P40 é do tipo FPSO sistema flutuante de produção, armazenamento e transferência de óleo SS - plataforma semi-submersível e produz. Ela processa, armazenam e transfere o óleo. Os FPSOs (Floating, Production, Storage and Offloading) são navios com capacidade para processar e armazenar o petróleo, e prover a transferência do petróleo e/ou gás natural. A plataforma P38 é do tipo SS, sistema flutuante, plataforma semi-submersível e não produz. Ela armazena e transfere o óleo. A plataforma PIV é do tipo navio-sonda, projetado para a perfuração de poços submarinos.

A política de gestão da Unidade de Negócio Amazônia está assim descrita: “A UN-AM, ciente de sua atuação em um ambiente de negócios cada vez mais competitivo e considerando o desenvolvimento de suas atividades em uma área ambientalmente única, a Amazônia, estabelece e cumpre uma política de gestão orientada para a excelência do desempenho, garantia da qualidade, conservação ambiental, prevenção de acidentes, proteção da saúde das pessoas e para a responsabilidade social.” Essa descrição é apresentada de forma alinhada à contribuição da Unidade como um todo para a missão da Petrobras, apresentada como: "Explorar e produzir gás natural e petróleo na Amazônia". A Província Petrolífera de Urucu, localizada no coração da Floresta Amazônica, a 650 quilômetros a sudeste de Manaus, teve os seus esforços recompensados em 1986 com a descoberta de óleo e gás em níveis comerciais. 


\section{ASPECTOS METODOLÓGICOS DA PESQUISA}

Este item é composto por abordagem de pesquisa, método, estratégia de pesquisa, unidades de análise, critérios de escolha dessas unidades, estratégias de coleta de dados, estratégias de análise e categorias de análise definidas.

Iniciando-se pela abordagem metodológica, contextualiza-se que nesta pesquisa se fez uso da abordagem qualitativa, tomando-se por base Chizzotti (2008). Reconhecidamente inserido na abordagem qualitativa, em vários campos de estudos, dentre eles a Administração, o método fenomenológico, respaldado por Moreira (2004) foi o que deu suporte a esta investigação, a fim de se fazer compreender o fenômeno estudado.

Como estratégia de pesquisa escolheu-se o estudo de caso, não obstante a limitação de generalizações, própria do estudo de caso, pelas seguintes razões: essa estratégia é abrangente e inclui tanto estudos de caso único quanto de múltiplos casos; os estudos de caso colocam mais ênfase em uma análise contextual completa de poucos fatos ou condições e suas inter-relações (Cooper e Schindler, 2003); tal estratégia, com base em Eisenhard (1989) pode ser realizada, dependendo das estratégias utilizadas para coleta, análise e interpretação dos dados; é apropriada, de acordo com Yin (2010), por: não exigir controle sobre eventos comportamentais; focalizar acontecimentos contemporâneos; acrescentar fontes de evidências como entrevistas de pessoas envolvidas nos acontecimentos que estão sendo estudados; realizar observação desses acontecimentos, documentos e artefatos; possibilitar a investigação de um fenômeno e seus conteúdos da vida real, quando as fronteiras entre o fenômeno e o contexto ainda não estão claramente evidentes.

As unidades de análise desta pesquisa são sete (três bases de apoio e quatro de operações) da organização brasileira Petrobras - Petróleo Brasileiro S/A. Foram analisadas, na região Sudeste, a UN Rio, bases Rio e Macaé, Plataformas P40, P38 e PIV. Na região Norte, a UN AM, bases Manaus e operacional de Urucu. O critério de escolha deste caso, envolvendo unidades com estruturas organizacionais remotas e não remotas da Petrobras se deveu a dois fatores: as unidades não remotas são as bases de apoio para as unidades remotas; as unidades com estruturas remotas são também confinadas, em mar e selva, o que permite investigar novas especificidades em um e outro contexto.

Quanto às estratégias de coleta de dados foram utilizadas três fontes de evidência, em consonância com a recomendação de Eisenhardt (1989) e Einsenhardt \& Graebner (2007) para a triangulação: entrevistas em profundidade, documentos fornecidos sobre especificidades da 
organização, em cada unidade de análise pesquisada, bem como em seu site, e observações. Essas observações foram feitas nos locais dessas organizações, quando visitadas para a realização das entrevistas.

No que se refere às estratégias para tratamento dos dados foram utilizadas: análise de conteúdo e análise reflexiva. Segundo Bardin (1977, p. 42), a análise de conteúdo é: "um conjunto de técnicas de análise das comunicações visando obter, por procedimentos sistemáticos e objetivos de descrição do conteúdo das mensagens, indicadores (quantitativos ou não) que permitam a inferência de conhecimentos relativos às condições de produção / recepção dessas mensagens". Para essa autora, a análise de conteúdo não deve ser nem doutrinária nem normativa. A análise reflexiva caracteriza-se pelo fato de que, todas as referências para dados empíricos são resultados de interpretação e reflexão (Vergara, 2005). A autora enfatiza que, na análise reflexiva, fundamentação teórica e coleta de dados empíricos caminham conjuntamente. Essas análises foram realizadas em cada categoria estabelecida a priori, com base em Vergara (2005): 'comportamento organizacional'; 'comprometimento organizacional'; 'gestão de pessoas'; e 'cultura organizacional'.

Selltiz, Wrightsman e Cook (2005), enfatizaram que as análises de conteúdo são realizadas com base em alguns critérios, quais sejam: as categorias de análise, usadas para a classificação do conteúdo, são clara e explicitamente definidas, de modo que outros indivíduos possam aplicá-las ao mesmo conteúdo, com vistas à verificação de suas conclusões; o pesquisador não pode selecionar e descrever apenas o que lhe parece interessante, mas precisa classificar metodicamente todo o material significativo de sua amostra; algum processamento quantitativo é utilizado, visando conseguir uma medida da importância e da acentuação, no material, das várias idéias encontradas, e permitir comparação com outras amostras de material.

A análise de conteúdo das entrevistas apoiou-se, predominantemente, em procedimentos interpretativos. Nesse ponto, o problema de pesquisa foi resgatado e os resultados obtidos foram confrontados com as teorias. A análise reflexiva foi utilizada para a interpretação dos dados empíricos oriundos das entrevistas e observações. Também foi utilizada a análise documental das especificidades de cada unidade remota. 
A Gestão de Pessoas e as Estratégias de Atração, Desenvolvimento e Retenção de Profissionais: O Caso Petrobras

\section{APRESENTAÇÃO E ANÁLISE DOS DADOS}

Para a elaboração das Tabelas 01, 02, 03 e 04, as unidades de codificação, representadas por palavras-tema e respaldadas por palavras-chave ou frases-chave, foram tomadas de segmentos do conteúdo das entrevistas, constituídos de significação para o objetivo da pesquisa. O primeiro resultado da análise de conteúdo foi obtido tomando-se as palavras-tema registradas nas entrevistas e reagrupadas em vinte e oito, consideradas como pertinentes ao objetivo da pesquisa, encontradas em todas as bases/plataformas, de modo a oferecer um parâmetro comum a todas elas. Do mesmo modo, procedeu-se ao agrupamento das palavras-chave ou frases-chave que melhor representassem as vinte e oito palavras-tema agrupadas como unidades de codificação em cada uma.

Para mostrar a presença ou ausência dessas palavras ou frases escolheu-se, auxiliarmente, fazer a contagem do número de vezes em que elas estiveram presentes ou ausentes no conteúdo de uma mesma entrevista. Para tanto, considerou-se o que foi dito por Bardin (1977): na análise qualitativa, a presença ou ausência de uma dada característica de conteúdo ou de um conjunto de características em um determinado fragmento de mensagem é o que se leva em consideração.

A partir da primeira sistematização, foi possível obter o resultado da categorização para as categorias de análise aqui representadas por: 'comportamento organizacional' (unidades de codificação 1 a 8), 'comprometimento organizacional' (unidades de codificação 9 a 16), 'gestão de pessoas' (unidades de codificação 17 a 23) e 'cultura organizacional' (unidades de codificação 24 a 28). 


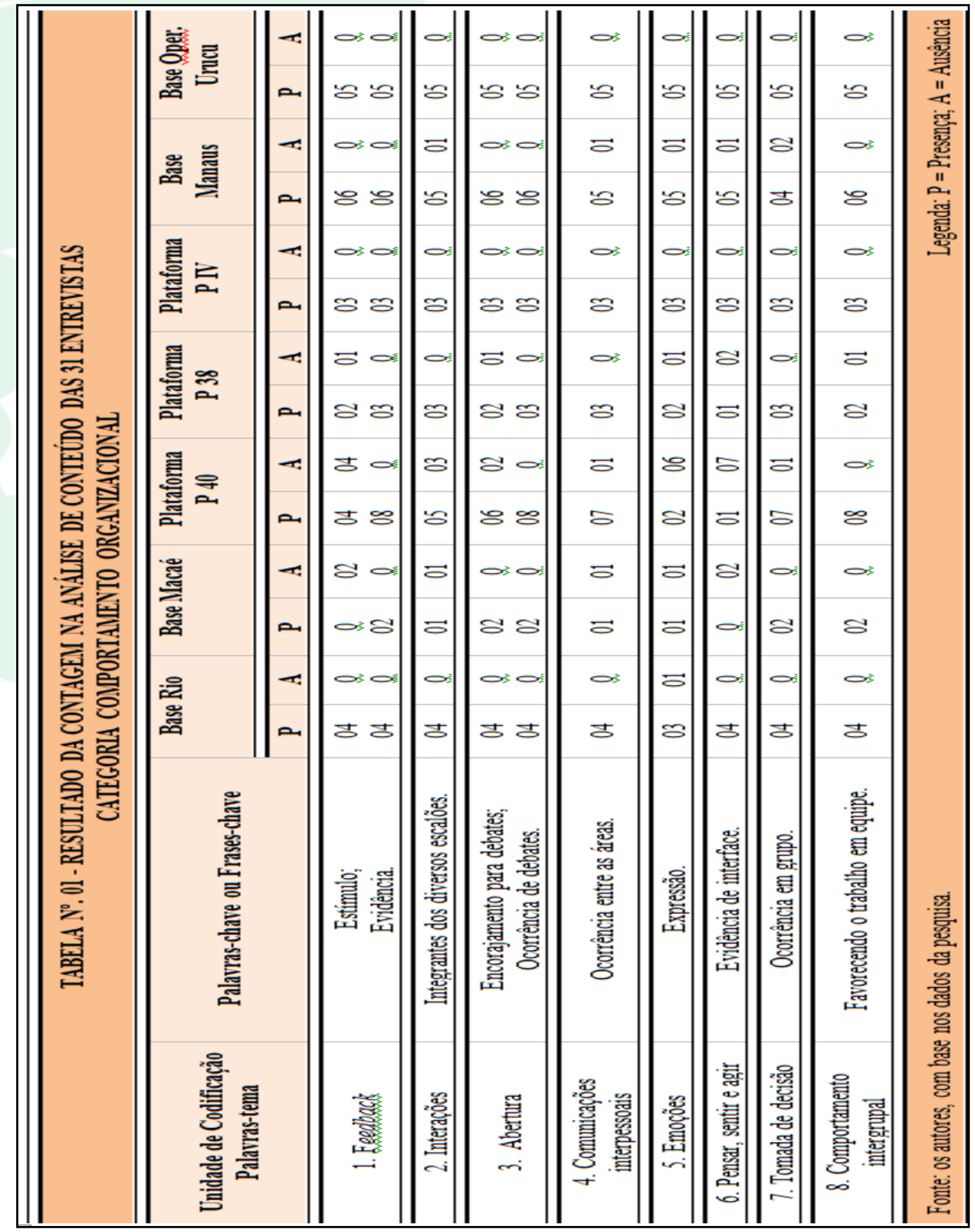


A Gestão de Pessoas e as Estratégias de Atração, Desenvolvimento e Retenção de Profissionais: O Caso Petrobras

Relembre-se que as unidades de codificação 1 a 8 dizem respeito às palavras-tema contidas na categoria comportamento organizacional. Os dados, em todas as bases e plataformas, contidos nessa categoria, encerram a percepção dos entrevistados acerca dos comportamentos de contribuição dos indivíduos, dos grupos e da estrutura, em prol dos resultados estratégicos da organização. Na base Rio, a contagem de presenças é totalitária na maioria absoluta dessas unidades de codificação, seguida de presenças expressivas na 5. Na base Macaé, as presenças são mostradas nas unidades de codificação 1 (palavra-chave 2), 3, 7 e 8 . As ausências contidas nas palavras-tema das unidades de codificação 1 (palavra chave 1), 2, 4, 5 e 6 chamam a atenção e podem ser conduzidas a um diálogo investigativo das razões. Na Plataforma P40, a contagem de presenças é totalitária nas unidades de codificação 1 (palavra-chave 2), 3 (frase-chave 2) e 8, seguida de presenças expressivas nas unidades de codificação 3 (frase-chave1), 4 e 7. As ausências contidas nas palavras-tema das unidades de codificação 1 (palavrachave 1), 5 e 6 podem ser conduzidas a um diálogo investigativo das razões. Na Plataforma P38, a contagem de presenças é totalitária nas unidades de codificação 1 (palavra-chave 2), 3 (frase-chave 2), 4 e 7, seguida de presenças expressivas nas unidades de codificação 1 (palavra-chave1), 3, 5 e 8 . As ausências contidas nas palavras-tema da unidade de codificação 6 são expressivas e podem ser conduzidas a um diálogo investigativo das razões. Na Plataforma PIV, a contagem de presenças é totalitária, em todas essas unidades de codificação. Na base Manaus, a contagem de presenças é totalitária nas unidades de codificação 1, 3 e 8, seguida de presenças expressivas nas unidades 2, 4, 5, 6 e 7. Na base de operações Urucu, a contagem de presenças é totalitária em todas as unidades de codificação. 
Nildes Pitombo Leite, Fabio Pitombo Leite \& Lindolfo Galvão Albuquerque

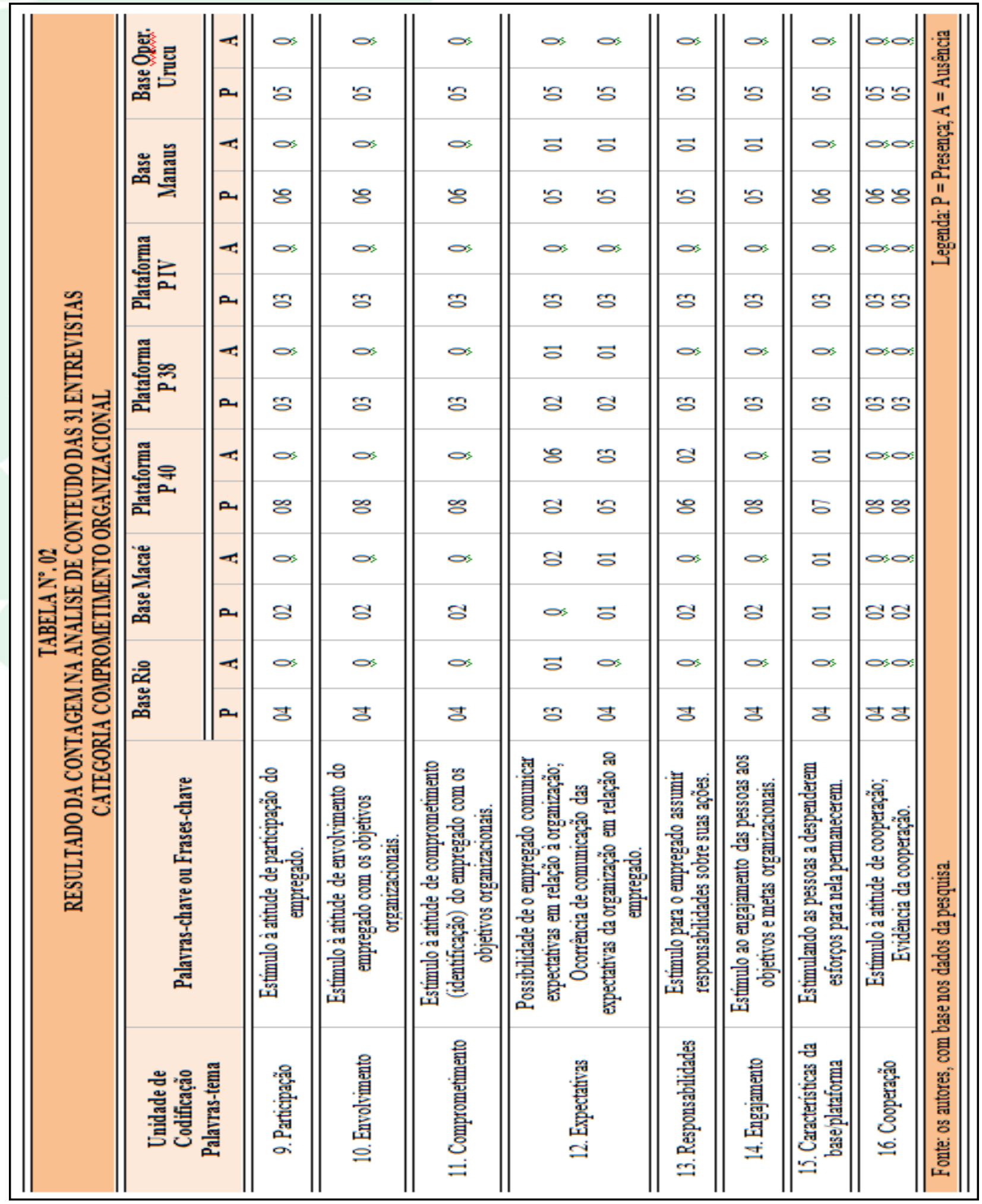


A Gestão de Pessoas e as Estratégias de Atração, Desenvolvimento e Retenção de Profissionais: O Caso Petrobras

Saliente-se que as unidades de codificação 9 a 16 estão voltadas para as palavras-tema contidas na categoria comprometimento organizacional. Os dados, em todas as bases e plataformas, contidos nessa categoria, encerram a percepção dos entrevistados acerca do orgulho e do empenho exercido pelos indivíduos em favor dos resultados estratégicos da organização. Na base Rio, a contagem de presenças é totalitária na maioria das unidades de codificação e expressiva na unidade de codificação 12 (frase-chave 1). Na base Macaé, a contagem de presenças é totalitária nas unidades de codificação 9,10,11, 13,14, e 16. As unidades de codificação 12, (frases-chave 2) e 15 mostram que as ausências se dividem com as presenças e se sobrepõem na 12, (frases-chave 1), tornando-se significativas para investigação das razões que estão nelas embutidas. Na Plataforma P40, a contagem de presenças é totalitária nas unidades de codificação 9,10, 11 14, e 16 e expressiva nas unidades de codificação 13 e 15. A unidade de codificação 12, em ambas as fraseschave, mostra que as ausências são significativas e necessitam de investigação das razões que estão nelas embutidas. Na Plataforma P38, a contagem de presenças é totalitária nas unidades de codificação 9, 10, 11, 13, 14, 15 e 16 e expressiva na unidade de codificação 12. Na Plataforma PIV, a contagem de presenças é totalitária, em todas essas unidades de codificação. Na base Manaus, a contagem de presenças é totalitária nas unidades de codificação 9, 10, 11, 15, e 16 e expressiva nas unidades de codificação 12, 13 e 14. Na base de operações Urucu, a contagem de presenças é totalitária, em todas as unidades de codificação. 


\begin{tabular}{|c|c|c|c|c|c|c|c|c|c|c|c|c|}
\hline \multirow{15}{*}{ 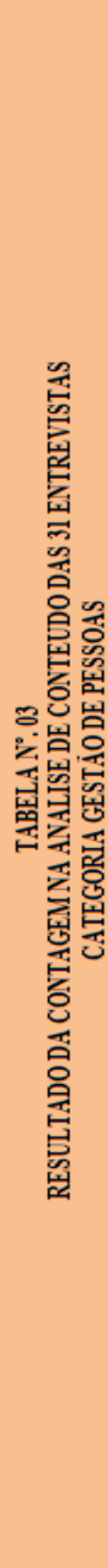 } & 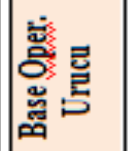 & a & $\infty$ & $\infty$ & os & os & $\infty$ & os & 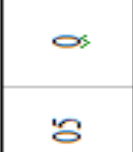 & os & os & \multirow{4}{*}{ 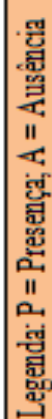 } \\
\hline & $\approx$ & $-\frac{\pi}{4}$ & $\vec{\sigma}$ & $\vec{\partial}$ & $\infty$ & $\infty$ & 8 & os & 8 & 8 & $\Leftrightarrow$ & \\
\hline & $\infty$ & ar. & 's & 's & 8 & 8 & t & 8 & to & t & 8 & \\
\hline & 距 & -4 & os. & $\infty$ & os & os & $\infty$ & $\infty$ & 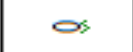 & os & $\infty$ & \\
\hline & 홈 & ar & 8 & 8 & 8 & 8 & 8 & 8 & 8 & 8 & 8 & \\
\hline & 㯺 & -4 & 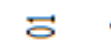 & $\infty$ & 8 & $\infty$ & $\overrightarrow{0}$ & $\infty$ & $\Leftrightarrow$ & $\infty$ & os & \\
\hline & s & ar & 8 & \% & $\vec{\sigma}$ & 8 & 8 & 8 & 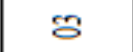 & \% & \% & \\
\hline & 㖘。 & -4 & s & os & ㅎㅇ & 8 & s & os & $\vec{\sigma}$ & ¿ & 8 & \\
\hline & 竦 & a. & 8 & 9 & 항 & 8 & 's & $g$ & 5 & 하 & 8 & \\
\hline & '渠 & -4 & $\infty$ & $\infty$ & os & 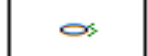 & $\overrightarrow{0}$ & os & $\infty$ & $\overrightarrow{0}$ & $\overrightarrow{0}$ & \\
\hline & ๓ั & ar & 8 & 8 & 8 & 8 & $\overrightarrow{0}$ & 8 & 8 & $\vec{\sigma}$ & $\overrightarrow{0}$ & \\
\hline & 울 & $\tau$ & os. & $\infty$ & os & $\infty$ & 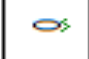 & 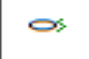 & 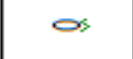 & $\infty$ & $\infty$ & \\
\hline & 品 & $\infty$ & 하 & 항 & 하 & 하 & 항 & t & t & 하 & 하 & \\
\hline & 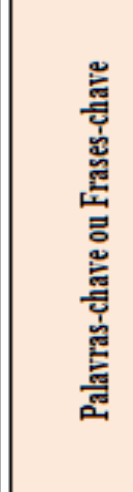 & & 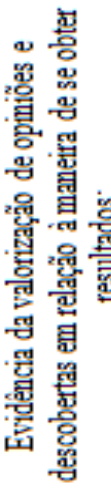 & 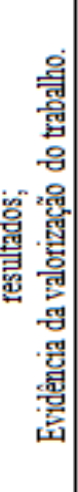 & 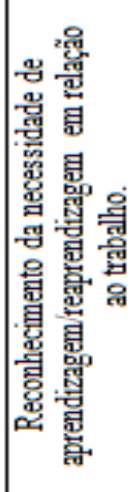 & 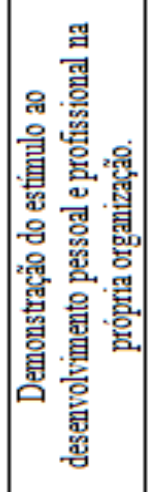 & 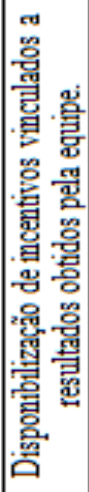 & 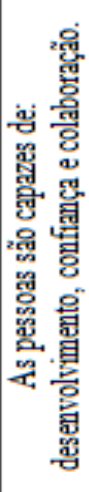 & 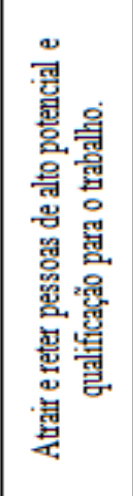 & 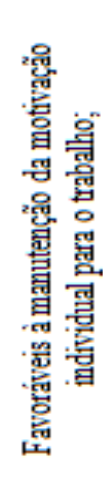 & 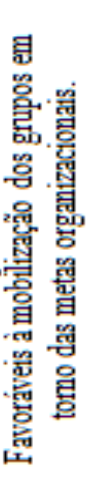 & 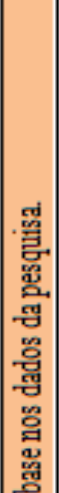 \\
\hline & 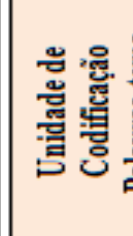 & & 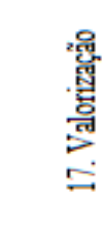 & & 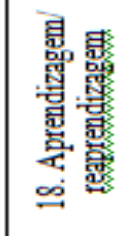 & 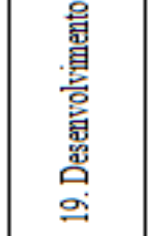 & $\begin{array}{l}\text { 总 } \\
\text { 曽 } \\
\text { 종 }\end{array}$ & 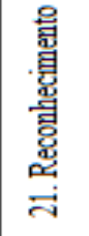 & 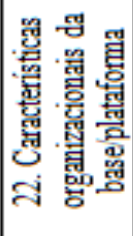 & 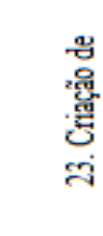 & & 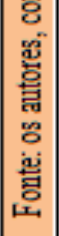 \\
\hline
\end{tabular}


A Gestão de Pessoas e as Estratégias de Atração, Desenvolvimento e Retenção de Profissionais: O Caso Petrobras

Enfatize-se que as unidades de codificação 17 a 23 referem-se às palavras-tema contidas na categoria gestão de pessoas. Os dados, em todas as bases e plataformas, contidos nessa categoria, encerram a percepção dos entrevistados, acerca da adoção de novas práticas de gestão, de modo a facilitar as ações estratégicas de desenvolvimento e resolução de conflitos entre as realidades offshore e onshore. Na base Rio, as presenças são totalizadoras em todas as unidades de codificação. Na base Macaé, as presenças são totalizadoras nas unidades de codificação 17, 18, 19, 21 e 22. As ausências observadas nas unidades de codificação 20 e 23 (ambas as frases-chave) denotam necessidade de investigação para a compreensão das razões. Na Plataforma P40, as presenças são totalizadoras nas unidades de codificação 17 (frase-chave 2) e 21; expressivas nas 17 (frase-chave 1), 19 e 23 (frasechave 2). As ausências observadas nas unidades de codificação 18, 20, e 23 (frase-chave 1) denotam necessidade de investigação para a compreensão das razões. Na Plataforma P38, as presenças são totalizadoras nas unidades de codificação 17 (frase-chave 2), 19, 21 e 23 e expressivas nas 17 (frase-chave 1) e 22. As ausências observadas na unidade de codificação 18 denotam necessidade de investigação para a compreensão das razões. Na Plataforma PIV, as presenças são totalizadoras em todas as unidades de codificação. Na base Manaus, as presenças são totalizadoras nas unidades de codificação 18, 19, 21 e 23 (frase-chave 2) e expressivas na 17. As ausências observadas nas unidades de codificação 20, 22 e 23 (frase-chave 1) denotam necessidade de investigação para a compreensão das razões. Na base de operações Urucu, as presenças são totalizadoras em todas as unidades de codificação. 
Nildes Pitombo Leite, Fabio Pitombo Leite \& Lindolfo Galvão Albuquerque

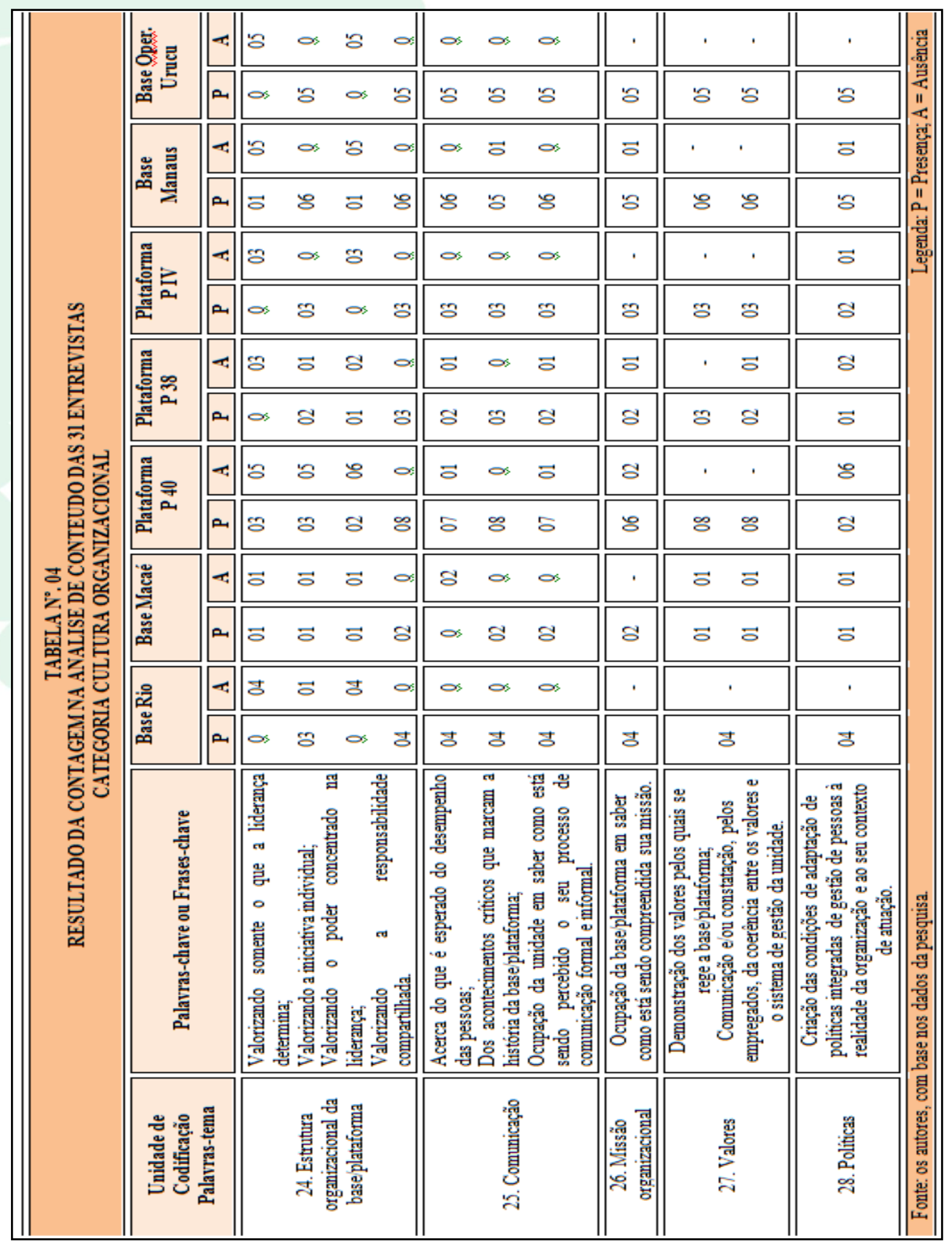


A Gestão de Pessoas e as Estratégias de Atração, Desenvolvimento e Retenção de Profissionais: O Caso Petrobras

Elucide-se que as unidades de codificação 24 a 28 estão no bojo das palavras-tema contidas na categoria cultura organizacional. Os dados, em todas as bases e plataformas, contidos nessa categoria, encerram a percepção do conhecimento que os indivíduos têm, acerca da visão, filosofia de atuação, missão e valores, em prol da estratégia de gestão de pessoas. Registre-se, na base Rio, a ausência encontrada na unidade de codificação 24 - estrutura organizacional da base/plataforma, com as frases-chave "valorizando somente o que a liderança determina" e "valorizando o poder concentrado na liderança" o que mostra o aspecto positivo da falta de centralização, reforçado pela presença totalitária da frase-chave "valorizando a responsabilidade compartilhada" e, significativa, da frase-chave "valorizando a iniciativa individual". As unidades de codificação 25, 26, 27 e 28 apresentam presenças absolutas, podendo denotar confirmação dos resultados percebidos nas demais unidades de codificação dessa categoria. Observe-se, na base Macaé, a divisão entre ausências e presenças, encontrada na unidade de codificação 24, com as frases-chave "valorizando somente o que a liderança determina", "valorizando a iniciativa individual" e "valorizando o poder concentrado na liderança". A presença absoluta aparece na frasechave "valorizando a responsabilidade compartilhada". Tal fato merece investigação. A unidade de codificação 25 (frases-chave 1) mostra ausência, enquanto as frases-chave 2 e 3 presenças. A 26 apresenta presença e as 27 e 28, divisão entre presença e ausência, podendo denotar necessidade de investigação das prováveis causas. Na Plataforma P40, elucide-se a ausência encontrada na unidade de codificação 24, com as frases-chave "valorizando somente o que a liderança determina", "valorizando a iniciativa individual" e "valorizando o poder concentrado na liderança". Encontra-se presença totalitária na frase "valorizando a responsabilidade compartilhada." As unidades de codificação 25 (frase-chave 2) e 28 apresentam ausências totalitárias, seguidas de ausências substanciais, nas unidades de codificação 25 (frases-chave 1 e 3) e 26, podendo denotar necessidade de investigação das prováveis causas. Saliente-se, na Plataforma P38, a ausência encontrada na unidade de codificação 24 , com as frases-chave "valorizando somente o que a liderança determina" e "valorizando o poder concentrado na liderança", reforçadas pela presença das frases "valorizando a responsabilidade compartilhada" e "valorizando a iniciativa individual". As unidades de codificação 25 (frases-chave 2), 26 e 28 apresentam presenças totalitárias e a 25 (frases-chave 1 e 3), presenças expressivas. As ausências, na unidade 28, podem apresentar necessidade de investigação das prováveis causas. Na Plataforma PIV, enfatize-se a ausência absoluta na unidade de codificação 24, com as frases-chave "valorizando somente o que a liderança determina" e "valorizando o poder concentrado na liderança", o que mostra a visão positiva com relação a poder e estrutura de comando. Tal percepção é reforçada pelas presenças totalizadoras das frases-chave 
"valorizando a responsabilidade compartilhada" e "valorizando a iniciativa individual." As unidades de codificação 25, 26, 27 e 28 apresentam presenças totalizadoras. Na base Manaus, saliente-se a ausência encontrada na unidade de codificação 24, com as frases-chave "valorizando somente o que a liderança determina" e "valorizando o poder concentrado na liderança", mostrando o aspecto positivo da falta de centralização, o que é reforçado pela presença significativa das fraseschave "valorizando a responsabilidade compartilhada" e "valorizando a iniciativa individual". A unidade de codificação 25 (frases-chave 1 e 3) apresenta presenças totalizadoras e presenças expressiva na frase-chave 2. Registrem-se, ainda, presenças totalizadoras na 27 e expressivas nas 26 e 28 . Na base de operações Urucu, enfatize-se a ausência absoluta na unidade de codificação 24, com as fraseschave "valorizando somente o que a liderança determina" e "valorizando o poder concentrado na liderança", reforçada pelas presenças totalizadoras das frases-chave "valorizando a responsabilidade compartilhada" e "valorizando a iniciativa individual". As unidades de codificação 25, 26, 27 e 28 apresentam presenças totalizadoras.

\section{DISCUSSÃO DOS RESULTADOS}

Uma vez apresentados os dados de todas as quatro categorias de análise, as discussões dos resultados desta pesquisa podem ser relacionadas ao modelo proposto por Ulrich (1998), notadamente no que se refere aos quatro papéis definidos como de RH, (e aí se inserem os profissionais das unidades de base investigadas) quais sejam:

1) administração de estratégias de gestão, na qual o papel se concentra na participação do processo de definição da estratégia organizacional e concebem estratégias e práticas de gestão de pessoas que sejam alinhadas à estratégia organizacional, transformando o profissional de $\mathrm{RH}$ em parceiro estratégico da organização. Associando ao que foi trazido por Albuquerque (2002) para a formulação da estratégia de gestão de pessoas, tem-se a observação do esforço engendrado pelas unidades estudadas, no sentido de contemplar os aspectos relativos às dimensões humanas, tanto nas áreas de trabalho quanto nos alojamentos e hotelarias dessas unidades. $\mathrm{O}$ desafio da gestão de pessoas na Petrobras é lidar com a diversidade cultural de todo o Brasil, reunida a bordo das plataformas e da base operacional de Urucu, percebendo, interagindo e capitalizando as contribuições. Os desafios de gestão de RH, nessas unidades de negócio, passam pela missão da corporação de "ser referência internacional, no segmento de energia, em gestão de pessoas, tendo seus empregados como seu maior valor.” A gestão de pessoas passou a assumir um papel importante no desenvolvimento da estratégia 
da organização, à medida que ajuda os gestores a cuidar, com mais propriedade, de atrair, desenvolver e reter as competências necessárias à realização dos objetivos organizacionais, considerando a capitalização das competências individuais que agregam valor aos grupos, às unidades de negócio e à organização.

2) administração de infra-estrutura da organização, cujo papel tradicional do especialista administrativo consiste em conceber e desenvolver processos eficientes para contratar, treinar, avaliar, premiar, promover e gerir o fluxo de funcionários na organização. Cada uma dessas unidades de negócio pesquisadas encontra-se, de alguma maneira, empenhada na tarefa de interpretar o ambiente no qual está inserida e construí-lo por intermédio de suas ações, quer escolhendo a melhor forma para o agrupamento de recursos humanos e materiais (departamentalização) ou consolidando a definição de autoridade, atividades e comunicação (atribuições), necessárias para cumprir a sua missão organizacional ou, ainda, cuidando de (departamentalização, comunicações e atribuições) para gerenciar a infra-estrutura denominada estrutura organizacional remota.

3) administração da contribuição dos funcionários, na qual o papel do defensor dos funcionários é enfatizado e cuja meta é obter maior envolvimento e competência do quadro de pessoal, por intermédio da provisão de recursos necessários aos empregados. Faz-se perceptível o movimento, nessas unidades investigadas, da busca constante pela criação de condições favoráveis ao engajamento, à participação, ao envolvimento e ao comprometimento das pessoas com os objetivos organizacionais, observando-se os cuidados, por parte dos gestores, com o ambiente externo no qual as unidades estão inseridas, destacando-se o caráter extremamente diferenciado das realidades do mar e da floresta. Relembre-se que Dessler (1996) ajudou a entender que funcionários, sob essa perspectiva, poderão fazer seu trabalho como se fossem responsáveis diretos pelas unidades, na medida em que, uma vez comprometidos, dão o melhor de si para a organização e não necessitarão dos olhos vigilantes de uma equipe de supervisão para realizar suas atividades. Os dados da pesquisa atestam a existência dos três elementos na geração do comprometimento organizacional apontados por Salancik (1977) como fundamentais para gerar comprometimento: a volição, a visibilidade e a irreversibilidade das ações.

4) administração da transformação e da mudança, que tem por objetivo assegurar capacidade para mudança organizacional, transformando o profissional de $\mathrm{RH}$ em agente de mudança. Na organização estudada, em 1997, com o término do monopólio, alguns problemas de mudança cultural ficaram evidenciados e, a partir de então, deu-se a criação das unidades de negócio e das gerências por ativos. Tal mudança aprimorou o processo de contribuição das pessoas, como 
organização integrada pelos ativos. Houve uma lacuna de dez anos sem contratação. Atualmente, os gestores ocupam-se em trabalhar a harmonização entre as gerações de antigos e de recém-chegados. As pessoas mais antigas são consideradas como propagadoras do orgulho, por todo o país, pois têm a visão de que não produzem petróleo para a Petrobras, mas contribuem para a responsabilidade social, regional e do Brasil.

A estratégia de gestão de pessoas, no contexto das unidades remotas confinadas analisadas, indica assumir como premissas básicas: a valorização dos talentos humanos; a atração e manutenção de pessoas de alto potencial e qualificação para o trabalho; a criação de condições favoráveis à motivação individual e à mobilização dos grupos em torno das metas organizacionais; a possibilidade de desenvolvimento profissional na própria organização; a disponibilização de incentivos vinculados a resultados obtidos pela equipe e adaptação de políticas integradas de recursos humanos à realidade da organização e ao seu contexto de atuação nas unidades de negócio. O regime de trabalho nas plataformas e na base operacional de Urucu é de 14 x 21(14 dias de trabalho confinado e 21 de folga, com férias anuais de 30) ou 15 x 27 (no qual as férias são diluídas na escala), o que só existe na Petrobras e é tido como muito complexo para gerir.

As práticas de gestão de pessoas vêm das diretrizes da corporação e suas especificidades são tratadas pelos gestores com liberdade plena de entender as necessidades das unidades e atuar sobre elas. São ferramentas adotadas pelas unidades de negócio para atender as estratégias de atrair, desenvolver, reter profissionais e minimizar conflitos. Percebe-se a mudança de foco de gestão de pessoas, antes em RH, para os gestores gerentes, por meio de programas de aprimoramento dos que são oriundos das áreas técnicas - engenharia, tais como: programa de reconhecimento e recompensa; ouvidoria Petrobras; pesquisa de ambiência; fale com o RH; disseminação de conhecimento; ambientação dos recém-chegados com acompanhamento dos antigos; acompanhamento social offshore; diálogos em desenvolvimento de equipes; desenvolvimento de supervisores; construção de relações profissionais; processo seletivo de nível médio, realizado localmente; trabalho de resgate das pessoas que atuam no regime 14 x 21, o qual representa um desafio para as unidades, pois implica retirar do foco, a incidência de horas extras como requisito para as pessoas participarem.

Na UN Rio, algumas dessas ferramentas são destacadas: sabadão, reunião para sugestões, reivindicações, cobranças e trocas, na qual a participação é livre e os gestores estão sempre presentes; política de convivência saudável para todos os embarcados, independente de serem da organização ou de terceirizadas; diálogo diário de segurança; reuniões semanais; programa de troca de feedback; desenvolvimento de equipes; desenvolvimento de supervisores; resolução de conflitos; 
visitas das assistentes sociais a bordo para levantamento de problemas sugeridos por pessoas embarcadas.

Na UN AM ocorrem as reuniões de comitês de segurança, meio-ambiente e gestão; as melhorias de infra-estrutura dos alojamentos; aplicação do adicional que contempla a diferença para reter os talentos na região; discussões acerca das possibilidades de desenvolver atividades rentáveis com a floresta em pé; definição de sistema de identificação de potenciais gerentes, em sintonia com as especificidades da unidade, pois só o corporativo não funcionaria; ajustamento das agendas para discussão dos procedimentos de busca de resultados, pelo fuso horário diferenciado; discussões sobre as implicações de busca de mecanismos, habilidades, participação e capitalização de conhecimentos das pessoas; ênfase aos valores segurança, saúde e meio-ambiente; quartas do conhecimento, com registro no sistema e representando um estímulo aos professores internos, o que vem retirando o estigma de que treinamento só ocorre quando se viaja para outra unidade.

Os entrevistados consideram as plataformas e a base operacional da selva, pelo confinamento, ambientes hostis e, por consequência, necessitam de interação, relacionamento cortês, ajuda mútua, lazer e convivência saudável. A infra-estrutura para atender esses requisitos é considerada excepcional e dá todo o suporte para as atividades serem desenvolvidas de forma colaborativa, de acordo com os dados da pesquisa.

Em suas particularidades, a UN Rio, assume que cada plataforma tem um perfil diferenciado. Alguns gestores ressaltaram que essa realidade eleva cada uma delas à condição de melhor escola de aprendizagem para exercer a sociabilidade, em virtude da diversidade de culturas, hábitos e costumes, convivendo em universo restrito. Os atrativos, nas plataformas, são de ordem financeira, familiar e de aprendizagem de vida. Ela pratica o acréscimo de hora extra para treinamento exclusivamente ligado a operação em águas profundas. A prática de feedback é a mais utilizada na plataforma P38, como principal ponto do relacionamento para saber ouvir e receber a crítica.

A UN AM, base Manaus tem como práticas de gestão: atendimento médico, inclusive para a população ribeirinha; adicionais; pesquisa constante para equiparação salarial; diálogo diário de segurança, com as especificidades da região, antes de iniciar a jornada de trabalho; palestras e oficinas a cada embarque; o contratado terceirizado recebe o tratamento como integrante da força de trabalho própria; reunião de gestão da operação na chegada para os 14 dias; PRECOPER Prevenção e Controle de Perdas - reuniões que ocorrem aos finais de semana e reúnem toda a força de trabalho da unidade. Para os entrevistados há necessidade de se exercitar o feedback com mais coragem em todas as unidades de negócio, sendo preciso que cada gestor acredite nessa necessidade. Eles consideram que dentro da base de Manaus é fácil, assim como dentro de cada 
turma nas plataformas. Em Urucu é mais complexo. O gerente fica na sede, alguns supervisores o fazem, outros não. Ainda se pratica o acréscimo de hora extra para treinamento nessa unidade de negocio, pois, não é fácil as pessoas participarem espontaneamente durante os 21 dias. O feedback é impactado também por essa ausência durante esses 21 dias.

As contribuições que a UN AM recebe são inúmeras e, todos afirmam saber da responsabilidade de substituir, em $70 \%$, o consumo de energia elétrica nas termoelétricas, por gás natural. Discussões diárias geram ações com respeito aos impactos ambientais e os entrevistados mostram que bombeio de gás é ação de muita responsabilidade, na qual as tomadas de decisão têm de ser rápidas. A clareza da sustentabilidade é o que norteia o desafio e está atrelada às metas de segurança, meio-ambiente e saúde. No que tange à responsabilidade ambiental, há o viveiro de orquidários com as espécies nativas para a reposição da flora nas áreas degradadas. Em relação à responsabilidade social, destaca-se o programa de combate à malária. No que tange à questão de saúde da força de trabalho, além do atendimento normal, a UTI aérea está sempre disponível, sem restrições de custos, para os casos de necessidade mais grave.

Os dados das entrevistas elucidam que a função do supervisor passa, também, por entender as necessidades dos seus supervisionados e verificar o que é melhor para eles, alocá-los aonde poderão render mais, valorizá-los no que são bons e ajudá-los, sempre. O rodízio de gerentes é tido como saudável. É preciso ficar atento às competências de pessoas das próprias unidades de negócio para a ascensão. Os canais de comunicação são: representantes dos empregados, posto de assistente social; coordenados, gerente, sindicato. Uma das dificuldades levantadas pelos entrevistados é como lidar com as pessoas que não se enquadram na função para a qual foram concursadas. Por outro lado, eles consideram que tal fato encerra um desafio, na medida em que podem ser verificadas as habilidades com as quais essas pessoas podem realizar melhor as suas atividades. Os desafios para a retenção de talentos nessas unidades estão contidos na natureza do trabalho, nos adicionais financeiros, na conveniência para o empregado, na estrutura familiar e no tempo de folga. $\mathrm{O}$ percentual, para os que trabalham embarcados de turno, é de $110 \%$ a mais que do administrativo, em razão do confinamento, das periculosidades e das intempéries. Há registro de insatisfação quando a pessoa é retirada do campo para a sede da base, pela perda de $60 \%$ dos adicionais. Na percepção dos entrevistados, a questão de retenção de talentos ameaça apresentar problemas desde o momento em que a organização deixou de ser monopolista, o que significa dizer que os integrantes das novas gerações podem fazer escolhas por outras organizações no futuro. No atual momento, a maioria das organizações que entram é associada à Petrobras. Já estão sendo desenvolvidos trabalhos preventivos, entretanto. A permanência das pessoas embarcadas exige muito dos gestores, 
em termos de comunicação e, ir ao campo, estar junto das pessoas, é a única forma de ver os problemas e ajudar a resolvê-los.

Ressalte-se a premissa de que, os fatores como o desenvolvimento e a revolução tecnológica (comunicação), que reduzem as distâncias, facilitam os desafios para atração, desenvolvimento e retenção de talentos e, no caso Petrobras, tais desafios permanecem potenciais, ma medida em que os regimes de trabalho são diferenciados, as famílias permanecem em seus locais de origem e os atrativos financeiros e do próprio regime de trabalho compensam o afastamento temporário desses colaboradores dos seus lares para as plataformas e a unidade de operações em Urucu. Particularmente, entretanto, há registro de perdas de excelentes profissionais e, em posição estratégica, implicando não há um mecanismo de reter os talentos, na UN AM, em Manaus, por conta de adaptações familiares à região.

\section{CONSIDERAÇÕES FINAIS}

Atrair, desenvolver e reter talentos são ações estratégicas consideradas importantes para os gestores de unidades com estruturas organizacionais remotas da Petrobras. Uma vez que a empresa já oferece o atrativo financeiro, o qual é considerado muito marcante, os gestores entram com as ações de suporte, pois, a atividade em sistema de confinamento é muito complexa, exigindo harmonia no convívio, colaboração, confiança, ambiência e cooperação. Os desafios enfrentados no trato com a gestão de pessoas, em sua acepção estratégica, geram mais engajamento, orgulho e melhoria da relação interpessoal entre os integrantes das equipes. O conceito de gerir pessoas, nessa realidade, é visto como mais importante do que as ferramentas. Olhos e ouvidos estão atentos para o que surge fora da normalidade, que possa afetar pessoas, material, máquinas e produção, sobretudo, que precise gerar soluções rápidas.

A sensibilidade ambiental, os impactos decorrentes de eventuais acidentes, a conscientização de que a Amazônia representa um patrimônio natural da humanidade e, como tal, a visibilidade internacional é um fato, são fatores que contribuem para a difusão de toda política de gestão da unidade. Em função das operações de exploração e produção de óleo e gás, desenvolvidas na Região Amazônica, torna-se imperativa a necessidade de considerar que, o conceito de sustentabilidade, presente em todas as atividades da Petrobras, jamais seja esquecido nessa unidade. A Petrobras encontra-se no índice Dow Jones de sustentabilidade, uma das principais referências do mundo para os investidores. Suas principais estratégias são a gestão da marca e a gestão de pessoas. Os valores que acompanham tais estratégias são cidadania e meio ambiente e transparência. A 
ocupação espacial, os processos, as tecnologias, as pesquisas científicas e o próprio modelo de gestão são orientados pelos temas e conceitos priorizados no processo de elaboração participativa das diretrizes de sustentabilidade, buscando o aprimoramento das suas atividades nessa região.

Em razão dessa mudança de foco de gestão de pessoas para os gestores gerentes, há um trabalho em desenvolvimento que visa a aprimorar a forma de gerir as pessoas. Um cuidado específico é observado no acompanhamento do trabalhador offshore, em que suas necessidades são ouvidas e as ações são empreendidas, como reunião de análise crítica com pauta colocada pela operação, realizada por videoconferência, por exemplo. O desafio das bases de apoio operacional é fazer o alinhamento do $\mathrm{RH}$, como consultoria interna, para o corpo gerencial nos processos das plataformas e da base operacional da floresta. O trabalho de gestão de pessoas é visto como perene, respaldado por um suporte organizacional de investimento elevado em capacitação. A forma como o gerente conduz suas atividades pode resultar em ações mais ou menos eficazes. Algumas situações precisam ser bem tratadas, a exemplo da retirada de uma pessoa do campo para a sede, pois, isso pode implicar prejuízos para a vida pessoal, o que repercute diretamente na produtividade profissional. Os atrativos para se trabalhar em unidades de negócios, como essas estudadas são de duas dimensões: econômica, com proporcional sobre férias e feriados para os que trabalham embarcados, considerado tão atraente que, uma das grandes dificuldades encontradas é recrutar quem tem experiência no mar para contribuir com uma equipe em terra; as pessoas podem morar em qualquer parte do Brasil e, a grande maioria não mora no local da base, não havendo necessidade de fazer deslocamentos com as famílias.

Enseje-se que esta pesquisa, em cuja natureza qualitativa baseada em estudo de caso encontra, em sua própria natureza, a limitação da falta de possibilidade de generalização dos resultados. Também fica registrado que os resultados obtidos são baseados nas percepções dos entrevistados e nas observações dos pesquisadores. Por outro lado, as possibilidades de contribuições oriundas desta pesquisa são: novas unidades de negócios, com estruturas organizacionais remotas, no Brasil e em outros países podem ser investigadas; mantendo o foco na pesquisa qualitativa e a investigação, que se constitui no objetivo principal desta pesquisa, pode-se enfatizar, por meio da técnica do grupo focal, não apenas as percepções individuais, mas aquelas oriundas das interações do coletivo, expressas nas estruturas discursivas e na defesa ou crítica de termos e aspectos relevantes desta pesquisa, como forma de verificação dos dados oriundos das entrevistas e das observações; novas pesquisas, investigando a influência dos estilos dos gestores na obtenção do comprometimento organizacional, podem ser realizadas; análise quantitativa sobre rotatividade voluntária também pode fazer parte dessas agendas de pesquisa; do ponto de vista 
A Gestão de Pessoas e as Estratégias de Atração, Desenvolvimento e Retenção de Profissionais: O Caso Petrobras

teórico este estudo de caso pode suscitar a curiosidade para desenvolver os construtos estudados em meio às especificidades das estruturas organizacionais remotas confinadas.

Além de ampliação do foco ora investigado, na academia, incluindo a possibilidade de investigação quantitativa com os mesmos construtos, esta pesquisa poderá servir de estímulo para novas investigações nas áreas de administração, sociologia, psicologia, economia e antropologia dentro de unidades com estruturas organizacionais remotas em outras organizações; outras organizações poderão desenvolver estudo comparativo das regiões onde tenham unidades remotas instaladas e a influência que essas unidades exercem no desenvolvimento socioeconômico local de cada uma delas; para a sociedade, as contribuições residem no retorno obtido, por intermédio dos cuidados simultâneos em formação e capacitação de mão-de-obra, educação, responsabilidade socioambiental, saúde e segurança, nas mais diversificadas regiões, pelos recônditos do Brasil.

\section{REFERÊNCIAS}

Albuquerque, L. G. (1987). O papel estratégico de recursos humanos. Universidade de São Paulo: São Paulo: USP.

Albuquerque, L. G. (1999). Estratégias de recursos humanos e competitividade. In M. M. F. Vieira, L. M. B. Oliveira (Eds.), Administração contemporânea: perspectivas e estratégias. São Paulo: Atlas.

Albuquerque, L. G. (2002). A gestão estratégica de pessoas. In M. T. L. Fleury et al. (Eds.), As pessoas na organização. São Paulo: Editora Gente.

Albuquerque, L. G., Leite, N. P. (Org.) (2009). Gestão de pessoas: perspectivas estratégicas. São Paulo: Atlas.

Anthony, W. P.; Perrewé, P. L. \& Kacmar, K. M. (1996). Strategic human resource management. Harcourt Brace Publisher \& Company. 
Bardin, L.(1977). Análise de conteúdo. Lisboa: Edições 70.

Becker, B. E., Huselid, M. A., Ulrich, D. (2001). Gestão estratégica de pessoas com scorecard: interligando pessoas, estratégia e performance. Rio de Janeiro: Campus.

Casado, T. (2002). O indivíduo e o grupo: A chave do desenvolvimento In M. T. L. Fleury et al. (Eds.), As pessoas na organização (pp. 235-246). São Paulo: Editora Gente.

Casado, T. (2007). Comportamento organizacional: fundamentos para a gestão de pessoas. In R. C. Santos (Ed.), Manual de gestão empresarial - conceitos e aplicações nas empresas brasileiras (pp. 212-233). São Paulo: Atlas.

Chizzotti, A. (2008). Pesquisa qualitativa em ciências humanas e sociais. Petropólis: Vozes.

Cooper, D. R., Schindler, P. S. (2003). Métodos de pesquisa em Administração. Porto Alegre: Bookman.

Davel, E., Vergara, S. C. (Eds.) (2001). Gestão com pessoas e subjetividade. São Paulo: Editora Atlas.

Demo, G. (2012). Políticas de Gestão de Pessoas nas organizações. São Paulo: Atlas.

Demo, G., Neiva, E. R., Nunes, I., Rozzett, K.. (Oct./Dec. 2012). Human resources management policies and practices scale. Brazilian Administration Review - BAR, 9(4), 395-420. Rio de Janeiro.

Dertouzos, M. L., Lester, R. K., Solow R. M. (1990). Made in America: regaining the productive edge. Cambridge: The MIT Press.

Dessler, G. (1996). Conquistando comprometimento: como construir e manter uma força de trabalho competitiva. São Paulo: Makron Books.

Dessler, G. (2003). Administração de recursos humanos. São Paulo: Prentice Hall.

Eisenhardt, K. M. (1989). Building theories from case study research.Academy of Management Review, v. 14, n. 4, p. 532-550.

Einsenhardt, K. M. \& Graebner, M. E. (2007). Theory building from cases: opportunities and challenges. Academyof Management Journal. v. 50 (1), p. 25-32.

Friedman, B. A. (2007). Globalization implications for human resource management roles. Employ Respons Rights Journal, (19), 157-171. 
A Gestão de Pessoas e as Estratégias de Atração, Desenvolvimento e Retenção de Profissionais: O Caso Petrobras

Guest, D. E. (1987). Human resource management and industrial relations. Journal of Management and Industrial Relations, 24(5), 503-521.

Leite, N. P., Albuquerque, L. G. (2009). Gestão estratégica de pessoas: conceito, evolução e visão. In: Albuquerque, L. G., Leite, N. P. Gestão de pessoas: perspectivas estratégicas, pp.3-16. São Paulo: Atlas.

Leite, N. R. P., Albuquerque, L. G. (Mai./Ago./ 2009a). Políticas e práticas de gestão de pessoas: peculiaridades de uma estrutura organizacional remota. Revista de Administração da UFSM ReA, 2(2), 370-394. Santa Maria: UFSM.

Leite, N. R. P., Albuquerque, L. G. (Jul./Set./2009b). Os desafios de gerir pessoas em uma estrutura organizacional remota. Revista de Gestão - REGE USP, 16(3), 81-96. São Paulo: FEA/USP.

Leite, N. R. P., Albuquerque, L. G. (Jan./Mar./2011). Gestão estratégica de pessoas, comprometimento e contrato psicológico: o caso Vale. Revista de Administração. RAUSP, 46(1), 19-31. São Paulo: FEA-USP.

Leite, N. R. P., Albuquerque, L. G. (Set./Dez. 2012). Gestão estratégica de pessoas nas organizações petroquímicas de Camaçari - Bahia. Revista Ibero-Americana de Estratégia RIAE, 11(3), 61-96. São Paulo: UNINOVE.

Leite, N. R. P., Leite, F. P., Albuquerque, L. G. (2012). Gestão do comportamento organizacional e gestão de pessoas: um estudo observacional. Revista de Gestão - REGE-USP, (19), 2, 279-296. São Paulo: FEA-USP.

Martin-Alcazar, F., Romero-Fernandez, P. M., Sanchez-Gardey, G. (2008). Human resource mnagement as a field of research. British Journal of Management, (19), 103-119.

Martín-Alcázar, F., Romero-Fernández, P. M., Sanchez-Gardey, G. (2005). Strategic human resource management: integrating the universalistic, contingent, configurational and contextual perspectives. The International Journal of Human Resource Management, 16(5), 633-659.

Moreira, D. A. (2004). Pesquisa em Administração: origens, usos e variantes do método fenomenológico. RAI - Revista de Administração e Inovação, (1)5-19. São Paulo: UNINOVE.

Petrobras' Corporate Information. (n.d.) Retrieved November 18, 2008, from http://www2.petrobras.com.br/ingles/ads/ads_Petrobras.html

Petrobras' Human Resources. (n.d.) Retrieved November 18, 2008, from http://www2.petrobras.com.br/ingles/ads/ads_Petrobras.html 
Salancik, G. R. (1977). Commitment and the control of organizational behavior and belief. In B. M. Staw \& G. R. Salancik (Eds.) New direction in organizational behavior (pp. 1-54). Chicago: St.Clair.

Schuler, R. S., Jackson, S. E. (1987). Linking competitions strategies with human resource management practice. Oxford: Academy of Management Executive.

Schuler, R. S. (1992). Strategic human resource management: linking the people with the strategic needs of the business. Organizational Dynamics, pp. 18-32, Summer.

Selltiz, C., Wrightsman, L.S., Cook, S. W. (2005). Métodos de pesquisa nas relações sociais. Vol. 2 - medidas na pesquisa social. São Paulo: EPU.

Steyart, C., Janssens, M. (1999). Human and inhuman resource management: saving the subject of harm organization. The Interdisciplinary Journal of Organizational, Theory and Society, (6), 2, 181-198.

Ulrich, D. (1997). Measuring human resources: An overview of practice and prescription for results. Human Resource Management, 36(3), New York.

Ulrich, D. (1998). Os campeões de recursos humanos: inovando para obter os melhores resultados. São Paulo: Futura.

Ulrich, D. (2000). Recursos humanos estratégicos. São Paulo: Ed. Futura.

Ulrich, D., Ulrich, W. (2011). Por que trabalhamos: como grandes líderes constroem organizações comprometidas que vencem. Porto Alegre: Bookman.

Ulrich, D., Allen, J., Brockbank, W.; Younger, J., Nyman, M. (2011). A transformação do RH: construindo os recursos humanos de fora para dentro. Porto Alegre: Bookman.

Wright, P., Snell, S. (2001). Toward an integrative view of strategic human resource management. Human Resource Management Review, v.1. n. 3, pp. 203-225.

Vergara, S. C. (2005). Métodos de pesquisa em administração. São Paulo: Atlas.

Yeung, A., Berman, B. (1997). Adding value through human resources: reorienting human resource measurement to drive business performance. Human Resource Management, (31), 3. New York.

Yin, R. (2010). Estudo de caso: planejamento e métodos. São Paulo: Bookman. 
A Gestão de Pessoas e as Estratégias de Atração, Desenvolvimento e Retenção de Profissionais: O Caso Petrobras

Recebido: 30/08/2013

Aprovado: 28/10/2013 